\title{
repisälud
}

This is the peer reviewed version of the following article:

Garcia-Lunar I, Pereda D, Santiago E, Solanes N, Nuche J, Ascaso M, Bobi J, Sierra F, Dantas AP, Galan C, San Antonio R, Sanchez-Quintana D, SanchezGonzalez J, Barbera JA, Rigol M, Fuster V, Ibanez B, Sabate M, GarciaAlvarez A. Effect of pulmonary artery denervation in postcapillary pulmonary hypertension: results of a randomized controlled translational study. Basic Res Cardiol, 2019. 114(2): p. 5

which has been published in final form at: https://doi.org/10.1007/s00395-018-0714-x 


\section{Effect of pulmonary artery denervation in postcapillary pulmonary hypertension: results of a randomized controlled translational study.}

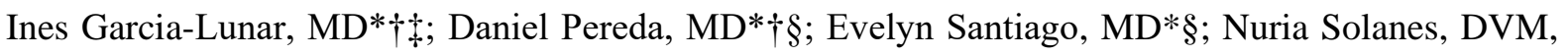

PhD§; Jorge Nuche, MD*\|; María Ascaso, MD§; Joaquim Bobí, DVM§; Federico Sierra, DVM*; Ana Paula Dantas, PhD§; Carlos Galán, DVM*†; Rodolfo San Antonio, MD§; Damián Sánchez-Quintana, MD, PhDI; Javier Sánchez-González, PhD\#; Joan Albert Barberá, MD, PhD§; Montserrat Rigol, DVM,

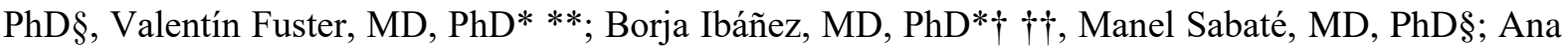
García-Álvarez, MD, PhD*§.

* Centro Nacional de Investigaciones Cardiovasculares Carlos III (CNIC), Madrid, Spain.

$†$ CIBER de Enfermedades Cardiovasculares (CIBERCV), Madrid, Spain.

† Hospital Universitario Quirónsalud Madrid, UEM, Madrid, Spain.

$\S$ IDIBAPS. Hospital Clínic, Barcelona, Spain.

||Hospital Universitario Doce de Octubre, Madrid, Spain.

If Departamento de Anatomía y Biología Celular, Facultad de Medicina, Universidad de Extremadura, Badajoz, Spain.

\# Philips Healthcare Iberia, Madrid, Spain.

** Zena and Michael A. Wiener Cardiovascular Institute, Icahn School of Medicine at Mount Sinai, New York, USA.

† IIS- Fundación Jiménez Díaz University Hospital, Madrid, Spain. 
Total word count: 8438 .

Short title: Denervation in chronic postcapillary pulmonary hypertension.

\section{Address for correspondence:}

\section{Ana García-Álvarez, MD, PhD}

E-mail: ana.garcia@cnic.es; anagarci@clinic.ub.es

Cardiology Department. Clinic Cardiovascular Institute.

Hospital Clínic. Villarroel 170, 08027, Barcelona, Spain.

Phone: +34 932279400 / Fax: +34 932279305.

ACKNOWLEDGMENTS: The authors thank Gonzalo J. López for the high-quality cardiac magnetic resonance examinations. Tamara Córdoba, Oscar Sanz, Nuria Valladares, Eugenio Fernández and the rest of the staff working in the animal facilities and CNIC's farm were outstanding in animal care and unconditional collaboration. Laura García, Alberto Barroso and Xavier Navarro provided us with the ablation clamps and catheters and assisted us during the denervation procedures. Paula Garcia-Lunar provided valuable support with tissue sampling when it was most needed.

SOURCES OF FUNDING: This work has been partially funded by the grant "Translational research project from the Sociedad Española de Cardiología" (to Dr. García-Álvarez) and by an unrestricted grant from Medtronic. The CNIC is supported by the Ministerio de Ciencia, Innovación y Universidades and the Pro CNIC Foundation, and is a Severo Ochoa Center of Excellence (SEV-2015-0505). IDIBAPS belongs to the CERCA Programme and receives partial funding from the Generalitat de Catalunya. 


\begin{abstract}
:
Background: There is scarce evidence for pulmonary artery denervation (PADN) as a potential treatment for chronic postcapillary pulmonary hypertension $(\mathrm{PH})$. We aimed to perform a proof-ofconcept of PADN in a translational model of chronic PH.
\end{abstract}

Methods and Results: Nineteen pigs with chronic postcapillary PH (secondary to pulmonary vein banding) were randomized to surgical-PADN (using bipolar radiofrequency clamps) or sham procedure. Additionally, 6 healthy animals underwent percutaneous-PADN to compare the pulmonary artery (PA) lesion generated with both approaches. In the surgical-PADN arm, hemodynamic evaluation and cardiac magnetic resonance (CMR) were performed at baseline and at 2 and 3-month follow-up. Histological assessment was carried out at the completion of the protocol. Eighteen pigs (6 following surgical-PADN, 6 sham and 6 percutaneous-PADN) completed the protocol. A complete transmural PA lesion was demonstrated using surgical clamps, whereas only focal damage to adventitial fibers was observed after percutaneous-PADN. In the surgical-PADN arm, the hemodynamic profile did not significantly differ between groups neither at baseline (mean pulmonary artery pressure [mPAP] median values of 32.0 vs. $27.5 \mathrm{mmHg}, \mathrm{P}=0.394$ and indexed pulmonary vascular resistance [iPVR] 5.9 vs. $4.7 \mathrm{WU} \mathrm{m}^{2}, \mathrm{P}=0.394$ for PADN/sham groups respectively) nor at any follow-up (mPAP of 35.0 vs. $35.0 \mathrm{mmHg}, \mathrm{P}=0.236$ and $\mathrm{PVR}$ of 8.3 vs. $6.7 \mathrm{WU}^{*} \mathrm{~m}^{2}, \mathrm{P}=0.477$ at third month in PADN/sham groups respectively). Surgical-PADN was not associated with any benefit in RV anatomy or function on CMR/histology.

Conclusions: In a large-animal model of chronic postcapillary PH, transmural PADN with surgical clamps was associated with a neutral pulmonary hemodynamic effect.

KEY WORDS: Pulmonary Hypertension; Magnetic Resonance Imaging; Denervation; Treatment. 
CONDENSED ABSTRACT: Ours is a proof-of-concept study of PADN with surgical bipolar radiofrequency clamps in a large-animal model of chronic postcapillary $\mathrm{PH}$. We have observed a neutral hemodynamic effect after complete PADN at 2 and 3-months follow-up and no benefit in RV anatomy or function on CMR or histology. Percutaneous-PADN produced only focal denervation. Our results do not support the use of PADN for the treatment of chronic postcapillary PH.

\section{ABBREVIATIONS:}

PH: Pulmonary hypertension.

PVR: Pulmonary vascular resistance.

RV: Right ventricular.

PA: Pulmonary artery.

PADN: Pulmonary artery denervation.

RHC: Right heart catheterization.

CMR: Cardiac magnetic resonance.

NA: Noradrenaline.

PV: Pulmonary vein.

CT: Computed tomography.

PAP: Pulmonary arterial pressure.

CO: Cardiac output.

LVEDP: Left ventricular end-diastolic pressure.

LV: Left ventricle. 


\section{INTRODUCTION:}

Pulmonary hypertension $(\mathrm{PH})$ is a prevalent condition characterized by an increase in pulmonary vascular resistance (PVR) and progressive right ventricular (RV) dysfunction associated with poor prognosis ${ }^{7,21}$. Currently, there are few therapeutic strategies available for $\mathrm{PH}^{7,14}$. Pulmonary artery (PA) vasodilators have shown a beneficial effect in pulmonary arterial hypertension but have failed to demonstrate a consistent benefit in other PH subgroups such as PH secondary to left heart disease or hypoxia (groups II and III, respectively, the most frequent causes of PH) ${ }^{14,26}$.

The pulmonary vascular bed is regulated by the nervous system ${ }^{25}$ and patients with chronic $\mathrm{PH}$ have increased levels of sympathetic activity ${ }^{1,16,28}$ that strongly contributes with the pathogenesis of the disease $^{27}$. Baroreceptors and sympathetic nerve fibers are located in or near the bifurcation area of the main pulmonary artery. In recent years, pulmonary artery denervation (PADN) using a percutaneous approach has emerged as a potential therapy for chronic arterial PH by reducing sympathetic stimulation of the pulmonary vasculature based on positive data from experimental animal studies. Moreover, in the recent non-randomized PADN-1 study the effect of PADN was evaluated ${ }^{5,12,19,24,30}$ in a heterogeneous group of $\mathrm{PH}$ patients ${ }^{3,4}$ with promising results, but the methodological limitations of this study leave the question whether PADN might be an effective therapy for patients with $\mathrm{PH}$ unanswered. Several randomized clinical trials evaluating the effect of PADN in chronic pulmonary arterial hypertension are currently ongoing. Despite the scarce preclinical evidence ${ }^{12}$ of the potential benefit of this therapy in chronic postcapillary $\mathrm{PH}$, it has been already applied to patients with $\mathrm{PH}$ secondary to left heart disease ${ }^{4,29}$.

We aimed to evaluate the effect of PADN using surgical bipolar radiofrequency ablation clamps in a large-animal model of chronic postcapillary PH. Particularly, we designed a translational study using 
state-of-the-art technology to assess the following specific objectives: (1) To evaluate the hemodynamic effect of PADN using right heart catheterization (RHC); (2) To evaluate the effect of PADN on biventricular anatomy and function using cardiac magnetic resonance (CMR); (3) To analyze the effect of PADN in pulmonary vascular and myocardial remodeling; and (4) To quantify the myocardial and systemic release of noradrenaline (NA) and activation of the renin-angiotensin-aldosterone system (RAAS). Additionally, (5) we aimed to characterize the lesion caused by the surgical bipolar radiofrequency clamps in comparison with the scar produced by percutaneous catheter-based PADN in healthy animals.

\section{METHODS:}

Study design and experimental model: The study was designed in two substudies and included a total of 25 castrated male Large-White pigs.

Substudy 1 aimed to assess the effect of PADN in chronic postcapillary PH using surgical bipolar radiofrequency clamps in terms of hemodynamics, cardiac anatomy and function and NA release. It included 19 4-week old Large-White pigs which previously underwent surgical pulmonary vein (PV) banding (of the inferior pulmonary venous confluent) to generate chronic postcapillary PH as previously described ${ }^{23}$. This procedure has been demonstrated to generate progressive chronic $\mathrm{PH}$ that becomes stable from the third month on, associated with advanced PH features on histopathology and CMR ${ }^{10,23}$ and has been already used to test potential therapies acting through the adrenergic system ${ }^{11}$. Two months after the induction of $\mathrm{PH}$, animals were randomized to PADN or sham procedure. Hemodynamic evaluation and cardiac magnetic resonance (CMR) were performed at baseline (before randomization) and at 2 and 3-month follow-up. Hemodynamic evaluation before the PV banding surgery was not performed because a previous study to characterize the PH model demonstrated normal PA pressures in all cases ${ }^{23}$. Histological assessment was carried out at the completion of the protocol.

Substudy 2 was designed to evaluate the feasibility of a catheter-based PADN approach and to characterize the lesion produced with the catheter in terms of damage to the nervous fibers at the PA 
adventitia, in comparison with the lesion generated with the surgical bipolar clamps. It included 6 healthy Large-White pigs ( $\approx 60-80 \mathrm{Kg}$ weight, similar to adult humans).

Our Institutional Animal Research Committee approved the study protocol. All animals received care in compliance with the Guide for the Care and Use of Laboratory Animals ${ }^{22}$. Before any procedure, animals were anesthetized with an intramuscular injection of ketamine $(20 \mathrm{mg} / \mathrm{kg})$, xylazine $(2 \mathrm{mg} / \mathrm{kg})$, and midazolam $(0.5 \mathrm{mg} / \mathrm{kg})$. Buprenorphine $(0.3 \mathrm{mg} / \mathrm{kg})$ was used for analgesia and animals were intubated.

All hemodynamic and imaging studies were performed under spontaneous ventilation, anesthesia with intravenous midazolam $(0.2 \mathrm{mg} / \mathrm{kg} / \mathrm{h})$, and continuous electrocardiographic and pulsioxymetric monitoring.

\section{Description of the PADN procedure using surgical bipolar radiofrequency clamps (substudy 1):}

Two months after the initial PV banding, animals were evaluated with RHC for hemodynamic assessment, CMR to measure biventricular volumes and function and cardiac computed tomography (CT) to confirm significant PV stenosis. Those animals with a resting mean pulmonary artery pressure (mean PAP) $\geq 25 \mathrm{mmHg}$ on RHC and a visible PV stenosis on cardiac CT were randomized to either PADN or sham procedure (Figure 1).

PADN was performed through a left lateral thoracotomy, 24-48 hours after the hemodynamic and imaging evaluation, using the Cardioblate ${ }^{\circledR}$ (Medtronic, USA) bipolar radiofrequency system at the level of the PA bifurcation and proximal portion of the right and left main PA branches ( 3 transmural applications in each site, Figure 2). Tissue impedance was monitored during radiofrequency applications to assure transmurality. Control animals underwent a sham operation as described above in which the radiofrequency was not applied. Blood samples $(\approx 20 \mathrm{~mL})$ were obtained in all animals from the left atrium through direct puncture, immediately before and 20 minutes after the PADN or sham procedure for NA and RAAS quantification. Hemodynamic evaluation, CMR and cardiac CT were repeated at 2 and 3-months follow-up and animals were euthanized thereafter (Figure 1). All 
analyses (hemodynamic, imaging, laboratory and histological) were performed blinded to allocation arm.

Description of the percutaneous PADN procedure (substudy 2): Six healthy Large-White animals were used for the percutaneous denervation of the main PA using the Simplicity ${ }^{\circledR}$ (Medtronic, USA) catheter. The catheter was inserted through the femoral vein and positioned under fluoroscopy guidance in the main PA. Four to six monopolar radiofrequency applications of up to 120 seconds were delivered to the PA wall beginning at the distal end of the artery and rotating circumferentially in a helical pattern. This was repeated for the other PA branch and for the main PA trunk (Figure 2). The Symplicity ${ }^{\circledR}$ generator uses an algorithm to monitor and control temperature, impedance, and power output to assure delivery of sufficient energy to obtain transmural lesions on each site. Hemodynamic evaluation, CMR and cardiac CT were performed 1 month after the ablation and animals were euthanized for histological analysis (Figure 1).

Hemodynamic assessment: Systemic blood pressure was monitored with a femoral arterial cannula (Arrow; Reading, PA, USA). RHC was performed using a Swan-Ganz catheter (Braun; Kronberg, Germany) inserted through the femoral vein and positioned under fluoroscopy to measure PAP and cardiac output (CO) as assessed by the thermodilution method. A pigtail catheter was placed inside the left ventricular cavity to measure left ventricular end-diastolic pressure (LVEDP). Additionally, a blood sample from the left ventricle $(\mathrm{LV}, \approx 20 \mathrm{~mL}$ ) was obtained through the pigtail catheter at the first followup evaluation ( 2 months after PADN/sham procedure) in all substudy 1 animals for NA and RAAS quantification. PVR was calculated as the difference between mean PAP and LVEDP divided by the CO in Wood units. Indexed PVR and CO by body surface area were estimated using the Brody's formula ${ }^{2}$.

CMR studies: All studies were performed on a 3.0-T TX Achieva scanner (Philips Medical Systems, the Netherlands), equipped with a 32-channel cardiac phased-array surface coil and retrospective 
electrocardiographic gating during spontaneous ventilation. Steady-state free precession cine sequences were acquired in 10-15 contiguous short axis slices covering both ventricles from base to apex with 30 cardiac phases each for the evaluation of ventricular volumes and function. Two-dimensional flow imaging (phase-contrast) was performed perpendicular to the main PA with a velocity-encoded gradient echo sequence using the minimum upper velocity limit without signal aliasing, as previously described 9 .

Analysis of CMR acquisitions was performed using specialized software (Extended MR Workspace®; Philips, The Netherlands) blinded to hemodynamic measurements and experimental allocation (PADN/sham). On cine images, biventricular endocardial contours were manually traced in enddiastole and end-systole and Simpson's method was used to calculate volumes and ejection fraction. RV trabeculations were included within the blood pool and the interventricular septum was adjudicated to the left ventricular mass. Wall thickness was measured on CMR cine short axis images at the midcavity level for the LV (interventricular septum and lateral wall) as well as the RV free wall. For phasecontrast analysis, the inner contour of the main PA was outlined in each cardiac phase to quantify the minimum and maximum areas, average velocities and stroke volumes. Ventricular volumes and masses and PA areas were adjusted to body surface area.

CT studies: To ensure the PV stenosis caused by the surgical banding, a CT study was performed in animals from substudy 1 prior to random allocation using a 64-slice scanner (Brilliance Philips, USA) with retrospective electrocardiographic gating. Additionally, in all animals, cardiac CT examinations were repeated at all follow-ups to exclude PA stenosis after the surgical or percutaneous ablation. Nonionic iodinated contrast agent $(30-40 \mathrm{~mL}$; Isovue 300) was injected through a peripheral vein at a rate of $4 \mathrm{~mL} / \mathrm{s}$ with a power injector, followed by a $30 \mathrm{~mL}$ saline flush. A bolus tracking technique was used to appropriately trigger image acquisition once attenuation in the RV reached a preset threshold of 100 HU.

Postprocessing of CT images was performed using dedicated software (Extended Brilliance Workspace 3.5; Philips, USA) and included multiplanar, volume- rendered, and shaded-surface display reconstructions. Short axis double-oblique dimensions were obtained at end-diastole for the main PA 
(1 $\mathrm{cm}$ proximal to the PA bifurcation) and left and right branches. Average diameters and areas were calculated for each vessel ${ }^{18}$.

Histological studies: At the completion of the study, all animals were euthanized with a lethal injection of pentobarbital sodium and the heart and lung parenchyma were excised for histological evaluation. A macroscopic block containing the PA trunk, bifurcation and both branches was stored for the descriptive analysis of the PADN lesions with both approaches (surgical and percutaneous) using a Masson's trichrome stain. The histological study involved: 1) a morphometric study of the lung parenchyma vasculature; 2) quantification of biventricular myocardial fibrosis; and 3) analysis of cardiomyocyte hypertrophy.

Pulmonary vascular remodeling was studied by double immunohistochemistry with anti-vonWillebrand factor to identify endothelial cells (1:200, A0082; Dako, Carpinteria, CA) and anti-smooth muscle actin to identify smooth muscle cells (1:100, M085101; Dako) antibodies and Verhoeff-van Gieson stain to identify elastic fibers. Ten randomly chosen arteries (100-300 $\mu \mathrm{m}$ diameter) per histological section from the inferior pulmonary lobe were analyzed. Similarly, ten randomly chosen small pulmonary arteries $(<100 \mu \mathrm{m})$ per section from the inferior pulmonary lobe were analyzed to study the histopathological changes in the small lung vessels. The quantification of collagen content was performed using a picrosirius red stain and ImageJ software to delineate the collagen percentage in 10 myocardium samples from each ventricle per animal. Cardiomyocyte size was analysed by double immunofluorescence technique using wheat germ agglutinin (1:500, W834, Invitrogen, Eugene, OR) and cardiac troponin I (1:200, sc-15368, Santa Cruz Biotechnology, Santa Cruz, CA) as primary antibodies. Three randomly chosen zones per histological section and 10 representative cardiomyocytes per zone were analyzed. All histological analyses were blinded to allocation arm.

NA and RAAS quantification: NA was extracted from plasma by a cis-diol-specific affinity gel, acylated and then quantitative levels of NA determined by a commercial Enzyme Inmunoassay (ELISA) kit (Labor Diagnostika Nord GmbH \& Co. KG). Similarly, angiotensin II and renin activity were 
measured using commercial ELISA kits (Merck, Millipore, USA). The same kits were used for quantification of NA, angiotensin II and renin in myocardial samples from the LV and RV.

Statistical analysis: Continuous variables are expressed as median (interquartile range). The MannWhitney U-test was used to compare baseline continuous variables between groups. The effect of the denervation procedure on the hemodynamic and CMR variables by subgroups was analyzed using the ANCOVA procedure to compare changes adjusted by the baseline value, the latter included as a covariate. Assumptions for ANCOVA were checked using the following methods: Normal P-P plots of regression; standardized residuals to confirm normally distributed errors; Lavene's test for the homogeneity of variances; lack of interaction between experimental group and baseline value; and homogeneity of regression slopes. All analyses were performed using SPSS® 20 (IBM Corp, USA.).

\section{RESULTS:}

\section{Substudy 1:}

\section{- Hemodynamic and cardiac performance effect of PADN using surgical bipolar radiofrequency clamps on chronic postcapillary $\mathbf{P H}$ :}

Nineteen Large-White pigs were required to achieve a final cohort of 12 animals with complete followup ( $\mathrm{n}=6$ PADN and $\mathrm{n}=6$ sham controls). Two animals with a mean PAP $<25 \mathrm{mmHg}$ were excluded prior to randomization and 5 more animals ( 3 in the PADN arm and 2 controls) died before completing the 3 month follow-up (Figure 1). Although not statistically significant, animals in the PADN arm had a slightly worse hemodynamic profile (higher indexed PVR and lower cardiac index) and RV performance (higher RV volumes and lower RV ejection fraction) than sham controls at baseline (Table $1)$.

There were no significant differences between both groups in PAP and PVR at 2- and 3-months followup (Table 2 and Figure 3). At the first follow-up (2 months after PADN) a significant decrease in systemic pressure was observed in denervated animals as compared with sham controls, which was maintained at the end of follow-up. Also, a trend towards a decrease in heart rate was observed in denervated individuals 2 months after PADN, but this trend disappeared at the end of follow-up (3 
months after the procedure, Table 2 and Figure 3). No significant differences in any other hemodynamic parameter were observed at either follow-up. Animals on the PADN arm had significantly lower weight at the 3-month follow-up than controls. Regarding CMR parameters, a trend towards larger biventricular volumes and masses was observed in the PADN arm after 2 months, and differences became statistically significant at the end of follow-up for indexed RV end-diastolic and end-systolic volumes, RV mass and LV end-diastolic volume (Table 3 and Figure 3). To discriminate whether heart rate might have influenced these results, we performed dedicated sensitivity analyses. After adjustment by heart rate in the ANCOVA analysis, only differences in indexed RVESV remained statistically significant at the third month follow-up between the PADN and sham groups (adjusted P values= 0.009 for indexed RVESV, 0.248 for indexed RVEDV, 0.288 for indexed RV mass and 0.248 for indexed LVEDV).

The PA average velocity was also significantly reduced in PADN animals at the end of follow-up. CT scans performed at every follow-up demonstrated normal anatomy of the PA and both branches thus excluding postprocedural PA stenosis. At the end of follow-up, main PA diameter and areas were 3.0 $(2.7-3.1) \mathrm{cm}$ and $6.8(5.5-7.3) \mathrm{cm}^{2}$ for PADN animals and $2.9(2.8-3.0) \mathrm{cm}$ and $6.0(5.8-6.5) \mathrm{cm}^{2}$ for sham controls ( $\mathrm{P}=0.762$ and 0.610 respectively). Similarly, no significant differences were observed in left or right PA dimensions (data not shown).

\section{- Microscopic histological analysis:}

1. Morphometric study of the lung parenchyma vasculature: There were no differences between groups in terms of pulmonary vascular remodeling in small $(<100 \mu \mathrm{m})$ or intermediate $(100-$ $300 \mu \mathrm{m}$ ) pulmonary vessels. In small pulmonary arteries, the areas (expressed as a percentage of the total vessel area) in the PADN/sham groups were respectively: $76.4 \%$ (74.2-77.3) vs. $77.3 \%$ (74.0-83.7), $\mathrm{P}=0.937$ for the arterial wall (medial + intima layers); and 23.6\% (22.7$25.8)$ vs. $22.7 \%(16.3-26.0)$ for the lumen. In intermediate pulmonary arteries, the areas in the PADN/sham groups were respectively: $53.45 \%$ (48.60-59.52) vs. $52.70 \%$ (46.94-58.68), 
$\mathrm{p}=0.699$ for the medial layer; $13.18 \%(11.59-13.81)$ vs. $14.83 \%(11.29-15.25), \mathrm{p}=0.240$ for the intimal layer; and $32.67 \%(27.60-38.88)$ vs. $32.51 \%(30.35-37.81), \mathrm{p}=0.937$ for the lumen.

2. Quantification of biventricular myocardial fibrosis: We found no statistically significant differences between groups in the amount of collagen content in both ventricles. The percentage of collagen in the PADN and sham groups were respectively: $4.50 \%(3.77-4.67)$ vs. $4.86 \%$ (4.36-4.94), $\mathrm{P}=0.310$ in the $\mathrm{RV}$; and $4.10 \%$ (3.09-6.02) vs. $3.34 \%$ (2.95-4.21), $\mathrm{P}=0.485$ in the LV (Figure 4).

3. Analysis of cardiomyocyte hypertrophy: We observed a greater degree of cardiomyocyte hypertrophy in denervated animals compared to the sham controls. This difference was statistically significant for the RV and did not reach statistical significance in the LV. The median cardiomyocyte perimeters for the PADN group and sham controls were respectively: $52.7 \mu \mathrm{m}(50.9-55.8)$ vs. $47.4 \mu \mathrm{m}$ (45.8-49.7), $\mathrm{P}=0.041$ for the $\mathrm{RV}$, and $51.9 \mu \mathrm{m}$ (46.3-56.8) vs. $48.6 \mu \mathrm{m}$ (48.4-48.9), $\mathrm{P}=0.394$ for the $\mathrm{LV}$ (Figure 4). There was a significant correlation between indexed RVESV ( $\mathrm{R}$ [Spearman-Rho] $=0.63, \mathrm{P}=0.028$ ) and histological cross-sectional area of the RV cardiomyocytes. Correlation between LV volumes and LV cardiomyocyte size did not reach statistical significance.

\section{- NA and RAAS quantification:}

There were no statistically significant differences in plasmatic NA, angiotensin II and renin absolute concentration or fold change (log2-transformed relative to the baseline levels) between both groups at any time-point (Table 4). We found a significant reduction in local NA levels at the RV (but not at the LV) 3 months after PADN. There were no significant differences in the myocardial expression of angiotensin II or renin (Table 5).

\section{Substudy 2: Feasibility of percutaneous PADN and comparison of the lesion produced with a catheter-based PADN strategy vs. surgical bipolar radiofrequency clamps:}

Six healthy Large-White animals underwent percutaneous PADN of the main PA and both proximal PA branches using a commercialized catheter. In all cases, according to the measurements of the 
navigation system, transmurality was met. There were no intra or postprocedural complications, demonstrating the technical feasibility of this approach.

The RHC performed 4 weeks later showed a normal hemodynamic profile in all cases (mean systolic pressure: 91.5 [91.0-94.0] $\mathrm{mmHg}$, mean pulmonary artery pressure: 16.0 [16.0-16.0] mmHg and cardiac output: 3.5 [3.0-3.9] L/min). CMR demonstrated normal biventricular anatomy and function (indexed RV end-diastolic volume: 55.8 [416-68.9] mL/m², indexed RV end-systolic volume: 19.3 [16.2-21.2] $\mathrm{mL} / \mathrm{m}^{2}$, indexed RV mass: 18.6 [17.0-20.2] g/ $\mathrm{m}^{2}$ and RV ejection fraction: 63.0 [60.0-66.0] \%). A small pericardial effusion was noted in 5 of the 6 animals. Normal PA anatomy and dimensions were found on the cardiac CT scans (main PA diameter: $2.2[2.0-2.6] \mathrm{cm}$ and area: $3.5[3.0-5.0] \mathrm{cm}^{2}$; left PA diameter: $1.6[1.4-1.7] \mathrm{cm}$ and area: $2.0[1.5-2.3] \mathrm{cm}^{2}$; and right PA diameter: $1.4[1.3-1.4] \mathrm{cm}$ and area: $\left.1.5(1.3-1.5) \mathrm{cm}^{2}\right)$.

The descriptive histological analysis of the lesions produced with the surgical bipolar radiofrequency clamps revealed fibrotic nerve fibers within the adventitia of the PA without visible axons (Figure 5 B). In contrast, in animals treated with the percutaneous catheter we found only focal damage to adventitial nerve fibers (coincident with the areas of radiofrequency application) coexisting with other healthy areas containing intact nerve fibers in the same arterial slice, thus confirming that denervation achieved with a catheter-based approach is not complete (Figure 5, C and D).

\section{DISCUSSION:}

The main results of this study are: 1) In a translational porcine model of chronic postcapillary $\mathrm{PH}$, PADN using surgical bipolar radiofrequency clamps was not associated with any improvement in hemodynamic parameters at follow-up; 2) In the same experimental setting, PADN was associated with significantly larger biventricular volumes and RV mass, that could be partially explained by a trend towards decreased in heart rate; 3) There was no significant difference in terms of pulmonary vascular remodeling or myocardial fibrosis between the PADN and sham groups. Denervated animals displayed a greater degree of cardiomyocyte hypertrophy in the RV; 4) We found a significant decrease in myocardial NA levels at the RV 3 months after PADN but no changes in circulating NA levels or in RAAS activation; 5) A catheter-based approach for PADN is feasible; however, lesions in the PA wall 
originated with this strategy are focal compared with those produced with surgical bipolar radiofrequency clamps and thus a complete stop in the innervation to the pulmonary vasculature is not achieved with currently available percutaneous PADN.

The pulmonary circulation has sympathetic innervation from neurons arising from the cervical and thoracic ganglia ${ }^{1,16}$. Sympathetic activation causes an increase in PVR and a decrease in pulmonary vascular compliance, thereby increasing PAP. Both responses are believed to be primarily mediated by a1-adrenoreceptors ${ }^{1}$. Patients with PAH have been demonstrated to have both systemic and cardiac sympathetic activation ${ }^{20,28}$. The neurohormonal axis has been therefore identified as a potential therapeutic target in $\mathrm{PH}$. In experimental studies performed in the 80s, an increase in mean PAP and PVR was observed in response to balloon distension of the main pulmonary artery and this increase was abolished by surgical denervation of the PA bifurcation as well as by chemical sympathectomy, thus indicating that the efferent branch of this neural reflex is predominantly mediated by the sympathetic nervous system ${ }^{15}$.

The first report on PADN as a potential therapy for PH was made by Chen et al in $2013^{5}$. In their experimental model of acute $\mathrm{PH}$, generated by a balloon occlusion of the left pulmonary interlobar artery in dogs, they demonstrated that radiofrequency ablation at the level of the PA bifurcation using a dedicated catheter was able to abolish this rise in pulmonary pressure. In a different porcine model of acute PH (generated by intravenous infusion of a thromboxane A2 analogue) ${ }^{24}$, Rothman et al found a blunted response in hemodynamic parameters to the thromboxane A2 infusion when compared to controls after percutaneous PADN. Although PH in this particular model was induced by acute vasoconstriction and not by progressive pulmonary vascular remodeling as in the human disease, the acute reduction in PAP achieved after PADN reinforced the idea that the sympathetic contribution to vasoconstriction might play a role in acute $\mathrm{PH}$. In addition, the authors provided histologic characterization of the ablation lesions but they did not report whether they also found undamaged nerve fibers in the PADN-treated animals, as we have. In the 2 experimental studies that have tested catheterbased PADN in chronic PH (induced by monocrotaline injection in dogs) ${ }^{19,30}$, a significant decrease in 
hemodynamic (PAP and PVR), RV remodeling parameters (Fulton index) and pulmonary vascular remodeling was observed. Particularly, in the study by Liu et $\mathrm{a}^{19}$, the authors reported a decrease in local RAAS activity at the level of the right heart and lung in denervated animals. Furthermore, Zhou et $\mathrm{al}^{30}$ showed a progressive and significant reduction in the sympathetic nerve conduction velocity together with axon loss and demyelinization in the PADN group. However, the monocrotaline injection itself in animals that did not develop PH and did not undergo PADN was also associated with altered sympathetic nerve conduction and ultrastructural nervous abnormalities when compared to healthy animals, that suggesting that it could reflect monocrotaline-related toxicity. Finally, in a very recent study $^{12}$, a combined surgical ${ }^{15}$ and chemical approach was used to produce PADN in rats with PH induced by banding of the ascending aorta. The authors reported a significant improvement in PA muscularization, hemodynamics and RV function as assessed by echocardiography. However, the low efficacy and high mortality rate of the animal model used to generate PH (78 animals were needed for a final number of 18 evaluated) may have biased the study outcomes.

Regarding the clinical studies, in 2013, Chen et al published the initial results of PADN-1, a nonrandomized clinical trial that compared the evolution of 21 patients with idiopathic $\mathrm{PH}$ not responding to medical therapy, of which 13 decided to undergo percutaneous PADN plus withdrawal of PH oral treatment vs. 8 controls in which prior medications were maintained. A significant decrease in mean PAP and an improvement in functional capacity and RV performance 3 months after percutaneous PADN was encountered ${ }^{3}$. Similar results were reported at the 1-year follow-up for 66 patients with PH of varied etiology in the Phase-II PADN-1 study ${ }^{4}$. Even though these results were promising, they were taken with caution by the PH community given the limitations of the study design (reduced number of patients, lack of randomization, absence of control group, withdrawal of targeted therapies in PADN patients, unusual baseline characteristics of the patient population not matching most idiopathic $\mathrm{PH}$ series and short-term follow-up) ${ }^{8,17}$ and the need for a controlled trial was internationally recognized ${ }^{13}$. Finally, in the very recent study by Zhang et $\mathrm{al}^{12}$, a series of 10 cases with PH secondary to HF treated with percutaneous PADN was reported. A global improvement in hemodynamics was found 6 months after the intervention but the heterogeneity of the group, concomitant treatment with sildenafil 
in 8 of the 10 cases and high variability in the hemodynamic and echocardiographic profile of the patients makes the response to PADN difficult to interpret. Moreover, some hemodynamic and echocardiographic responses are particularly controversial, like the decrease in LVEDP and pulmonary capillary wedge pressure reported.

Group $2 \mathrm{PH}$, characterized by increased pulmonary arterial wedge pressure, is the most prevalent and specific-treatment orphan PH type. Since very recently ${ }^{12}$, there was no preclinical evidence regarding the potential beneficial effect of PADN in postcapillary PH. This is why we decided to perform a proofof-concept experimental study using a well-established translational porcine model of chronic postcapillary $\mathrm{PH}^{10,23}$. Unlike all prior PADN studies, we used surgical bipolar radiofrequency clamps for the PADN procedures to ensure a complete and reproducible nervous isolation of the pulmonary vasculature instead of using the percutaneous approach that has been applied so far. In fact, on the basis of our histological analyses, the catheter-based approach generates focal adventitial damage without complete disruption of the innervation as opposed to the injury produced by the clamps. We found a significant reduction in NA levels at the RV in denervated animals 3 months after the procedure, this supporting the efficacy of the surgical-PADN approach.

Our study shows a neutral hemodynamic effect after complete PADN at 2- and 3-months follow-up. Moreover, in terms of biventricular remodeling we observed higher ventricular volumes and masses in denervated animals at follow-up, and greater cardiomyocyte hypertrophy on the RV. The presence of a slightly (non-significant) worse hemodynamic baseline profile in the animals that were subsequently randomized to PADN might explain a more unfavorable remodeling in this subgroup. Besides, although non-statistically significant at the third month follow-up, lower heart rate in PADN animals might have partially accounted for larger biventricular end-diastolic volumes. However, the increase in indexed RVESV in the PADN group was heart-rate independent and associated with RV cardiomyocyte hypertrophy on histology.

The heart is innervated by both parasympathetic and sympathetic fibers. Whereas the parasympathetic fibers cause a decrease in chronotropy and inotropy via cholinergic action on cardiac M2 receptors, the sympathetic fibers act on $\beta 1$-adrenergic receptors increasing chronotropy and inotropy of the heart ${ }^{27}$. There is evidence regarding the relationship between impaired parasympathetic activity and RV 
dysfunction in pulmonary hypertension ${ }^{6}$. Therefore, whereas sympathetic denervation might have a beneficial effect over the heart, parasympathetic denervation could have the opposite effect. In our experimental study we performed a complete transmural PA denervation using radiofrequency clamps. A disbalanced sympathetic/parasympathetic denervation favouring the latter might have a deleterious effect on RV remodeling. However, we acknowledge that further research on translational models is needed to confirm the potential deleterious effect of PADN on RV performance.

The PA average velocity was also significantly lower at 3-month follow-up in PADN animals, which may be related to abnormal PA flow dynamics in the absence of macroscopic PA stenosis. We did not find significant differences between the groups in the amount of myocardial fibrosis or the degree of pulmonary vascular remodeling. Given the difference with previous reports, it remains to be elucidated whether a partial and more indirect denervation caused by a catheter-based approach (since the radiofrequency is delivered from the inside to the outside of the PA) could somehow be more effective than a complete nervous isolation generated by the surgical clamps applied directly at the external surface of the PA. In fact, complete PADN in this specific model with high postcapillary pressure could hypothetically have worsened pulmonary congestion thus resulting in negative effects as previously observed with other pulmonary vasodilators when applied to group $2 \mathrm{PH}$ patients. We did not find differences in LV filling pressures, oxygen saturation or degree of pulmonary congestion on CT between the groups. Nonetheless, this possibility cannot be fully excluded.

Several limitations of this study should be addressed. First, sample sizes were small and therefore randomization did not completely balance all baseline characteristics. Second, our pig model of postcapillary $\mathrm{PH}$ does not represent the full spectrum of patients with group $2 \mathrm{PH}$ because systolic function of the LV remains conserved. Histological comparison regarding the PA lesion generated with both approaches was performed at a different time-point ( 3 months after surgical PADN and 1 month after percutaneous PADN) although it is very unlikely that the percutaneous PA lesion could be greater later on follow-up. 


\section{CONCLUSION:}

The present study shows that in a large-animal model of chronic postcapillary PH, PADN with surgical bipolar radiofrequency clamps was associated with a neutral effect in terms of pulmonary hemodynamics. Moreover, surgical-PADN was not associated with any benefit in RV anatomy or function on CMR or histology. A catheter-based PADN approach is feasible but produces incomplete PADN. Further studies evaluating the effect of incomplete percutaneous PADN in postcapillary PH would be desirable.

CONFLICT OF INTEREST: This work has been partially funded by an unrestricted grant from Medtronic.

\section{REFERENCES:}

1. Barnes PJ, Liu SFn(1995). Regulation of pulmonary vascular tone. Pharmacol Rev 47:87-131

2. Brody S (1928). A Comparison of Growth Curves of Man and Other Animals. Science 67:43-46.10.1126/science.67.1724.43

3. Chen SL, Zhang FF, Xu J, Xie DJ, Zhou L, Nguyen T, Stone GW (2013). Pulmonary artery denervation to treat pulmonary arterial hypertension: the singlecenter, prospective, first-in-man PADN-1 study (first-in-man pulmonary artery denervation for treatment of pulmonary artery hypertension). J Am Coll Cardiol 62:1092-1100.10.1016/j.jacc.2013.05.075

4. Chen SL, Zhang H, Xie DJ, Zhang J, Zhou L, Rothman AM, Stone GW (2015). Hemodynamic, functional, and clinical responses to pulmonary artery denervation in patients with pulmonary arterial hypertension of different causes: phase II results from the Pulmonary Artery Denervation-1 study. Circ Cardiovasc Interv 8:e002837.10.1161/CIRCINTERVENTIONS.115.002837

5. Chen SL, Zhang YJ, Zhou L, Xie DJ, Zhang FF, Jia HB, Wong SS, Kwan TW (2013). Percutaneous pulmonary artery denervation completely abolishes experimental pulmonary arterial hypertension in vivo. Eurolntervention 9:269276.10.4244/EIJV9I2A43

6. da Silva Goncalves Bos D, Van Der Bruggen CEE, Kurakula K, Sun XQ, Casali KR, Casali AG, Rol N, Szulcek R, Dos Remedios C, Guignabert C, Tu L, Dorfmuller P, Humbert M, Wijnker PJM, Kuster DWD, van der Velden J, Goumans MJ, Bogaard 
HJ, Vonk-Noordegraaf A, de Man FS, Handoko ML (2018). Contribution of Impaired Parasympathetic Activity to Right Ventricular Dysfunction and Pulmonary Vascular Remodeling in Pulmonary Arterial Hypertension. Circulation 137:910924.10.1161/CIRCULATIONAHA.117.027451

7. Galie N, Humbert M, Vachiery JL, Gibbs S, Lang I, Torbicki A, Simonneau G, Peacock A, Vonk Noordegraaf A, Beghetti M, Ghofrani A, Gomez Sanchez MA, Hansmann G, Klepetko W, Lancellotti P, Matucci M, McDonagh T, Pierard LA, Trindade PT, Zompatori M, Hoeper M, Aboyans V, Vaz Carneiro A, Achenbach S, Agewall S, Allanore Y, Asteggiano R, Paolo Badano L, Albert Barbera J, Bouvaist H, Bueno H, Byrne RA, Carerj S, Castro G, Erol C, Falk V, Funck-Brentano C, Gorenflo M, Granton J, lung B, Kiely DG, Kirchhof P, Kjellstrom B, Landmesser U, Lekakis J, Lionis C, Lip GY, Orfanos SE, Park MH, Piepoli MF, Ponikowski P, Revel MP, Rigau D, Rosenkranz S, Voller H, Luis Zamorano J (2016). 2015 ESC/ERS Guidelines for the diagnosis and treatment of pulmonary hypertension: The Joint Task Force for the Diagnosis and Treatment of Pulmonary Hypertension of the European Society of Cardiology (ESC) and the European Respiratory Society (ERS): Endorsed by: Association for European Paediatric and Congenital Cardiology (AEPC), International Society for Heart and Lung Transplantation (ISHLT). Eur Heart J 37:67119.10.1093/eurheartj/ehv317

8. Galie N, Manes A (2013). New treatment strategies for pulmonary arterial hypertension: hopes or hypes? J Am Coll Cardiol 62:11011102.10.1016/j.jacc.2013.06.032

9. Garcia-Alvarez A, Fernandez-Friera L, Garcia-Ruiz JM, Nuno-Ayala M, Pereda D, Fernandez-Jimenez R, Guzman G, Sanchez-Quintana D, Alberich-Bayarri A, Pastor-Escuredo D, Sanz-Rosa D, Garcia-Prieto J, Gonzalez-Mirelis JG, Pizarro G, Jimenez-Borreguero LJ, Fuster V, Sanz J, Ibanez B (2013). Noninvasive monitoring of serial changes in pulmonary vascular resistance and acute vasodilator testing using cardiac magnetic resonance. J Am Coll Cardiol 62:16211631.10.1016/j.jacc.2013.07.037

10. Garcia-Alvarez A, Garcia-Lunar I, Pereda D, Fernandez-Jimenez R, SanchezGonzalez J, Mirelis JG, Nuno-Ayala M, Sanchez-Quintana D, Fernandez-Friera L, Garcia-Ruiz JM, Pizarro G, Aguero J, Campelos P, Castella M, Sabate M, Fuster V, Sanz J, Ibanez B (2015). Association of myocardial T1-mapping CMR with hemodynamics and RV performance in pulmonary hypertension. JACC Cardiovasc imaging 8:76-82.10.1016/j.jcmg.2014.08.012

11. Garcia-Alvarez A, Pereda D, Garcia-Lunar I, Sanz-Rosa D, Fernandez-Jimenez R, Garcia-Prieto J, Nuno-Ayala M, Sierra F, Santiago E, Sandoval E, Campelos P, Aguero J, Pizarro G, Peinado VI, Fernandez-Friera L, Garcia-Ruiz JM, Barbera JA, Castella M, Sabate M, Fuster V, Ibanez B (2016). Beta-3 adrenergic agonists reduce pulmonary vascular resistance and improve right ventricular performance in a porcine model of chronic pulmonary hypertension. Basic Res Cardiol 111:49.10.1007/s00395016-0567-0

12. Hang Z, Wande Y, Shaoliang C (2018). EXPRESS: Pulmonary artery denervation improves hemodynamics and cardiac function in pulmonary hypertension secondary to heart failure. Pulm Circ: 2045894018816297.10.1177/2045894018816297

13. Hoeper MM, Galie N (2016). Letter by Hoeper and Galie Regarding Article, "Hemodynamic, Functional, and Clinical Responses to Pulmonary Artery Denervation in Patients With Pulmonary Arterial Hypertension of Different Causes: Phase II Results 
From the Pulmonary Artery Denervation-1 Study". Circ Cardiovasc Interv 9:e003422.10.1161/CIRCINTERVENTIONS.115.003422

14. Hoeper MM, McLaughlin VV, Dalaan AM, Satoh T, Galie N (2016). Treatment of pulmonary hypertension. Lancet Respir Med 4:323-336.10.1016/S22132600(15)00542-1

15. Juratsch CE, Jengo JA, Castagna J, Laks MM (1980). Experimental pulmonary hypertension produced by surgical and chemical denervation of the pulmonary vasculature. Chest;77:525-530

16. Kummer W (2011). Pulmonary vascular innervation and its role in responses to hypoxia: size matters! Proc Am Thorac Soc 8:471-476.10.1513/pats.201101-013MW 17. Leopold JA (2015). Catheter-based therapies for patients with medicationrefractory pulmonary arterial hypertension. Circ Cardiovasc Interv;8:e03332.10.1161/CIRCINTERVENTIONS.115.003332

18. Lin FY, Devereux RB, Roman MJ, Meng J, Jow VM, Simprini L, Jacobs A, Weinsaft JW, Shaw LJ, Berman DS, Callister TQ, Min JK (2009). The right sided great vessels by cardiac multidetector computed tomography: normative reference values among healthy adults free of cardiopulmonary disease, hypertension, and obesity. Acad Radiol;16:981-987.10.1016/j.acra.2009.02.013

19. Liu C, Jiang XM, Zhang J, Li B, Li J, Xie DJ, Hu ZY (2016). Pulmonary artery denervation improves pulmonary arterial hypertension induced right ventricular dysfunction by modulating the local renin-angiotensin-aldosterone system. BMC Cardiovasc Disord 16:192.10.1186/s12872-016-0366-4

20. Mak S, Witte KK, Al-Hesayen A, Granton JJ, Parker JD (2012). Cardiac sympathetic activation in patients with pulmonary arterial hypertension. Am J Physiol Regul Integr Comp Physiol 302:R1153-1157.10.1152/ajpregu.00652.2011

21. McLaughlin VV, Archer SL, Badesch DB, Barst RJ, Farber HW, Lindner JR, Mathier MA, McGoon MD, Park MH, Rosenson RS, Rubin LJ, Tapson VF, Varga J, American College of Cardiology Foundation Task Force on Expert Consensus D, American Heart A, American College of Chest P, American Thoracic Society I, Pulmonary Hypertension A (2009). ACCF/AHA 2009 expert consensus document on pulmonary hypertension a report of the American College of Cardiology Foundation Task Force on Expert Consensus Documents and the American Heart Association developed in collaboration with the American College of Chest Physicians; American Thoracic Society, Inc.; and the Pulmonary Hypertension Association. J Am Coll Cardiol;53:1573-1619.10.1016/j.jacc.2009.01.004

22. National Research Council (U.S.). Committee for the Update of the Guide for the Care and Use of Laboratory Animals., Institute for Laboratory Animal Research (U.S.), National Academies Press (U.S.). Guide for the care and use of laboratory animals. 8th ed. Washington, D.C.: National Academies Press,; 2011:xxv, 220 p.

23. Pereda D, Garcia-Alvarez A, Sanchez-Quintana D, Nuno M, Fernandez-Friera L, Fernandez-Jimenez R, Garcia-Ruiz JM, Sandoval E, Aguero J, Castella M, Hajjar RJ, Fuster V, Ibanez B (2014). Swine Model of Chronic Postcapillary Pulmonary Hypertension with Right Ventricular Remodeling: Long-Term Characterization by Cardiac Catheterization, Magnetic Resonance, and Pathology. J Cardiovasc Transl Res.10.1007/s12265-014-9564-6

24. Rothman AM, Arnold ND, Chang W, Watson O, Swift AJ, Condliffe R, Elliot CA, Kiely DG, Suvarna SK, Gunn J, Lawrie A (2015). Pulmonary artery denervation reduces pulmonary artery pressure and induces histological changes in an acute porcine model of pulmonary hypertension. Circ Cardiovasc Interv 8:e002569.10.1161/CIRCINTERVENTIONS.115.002569 
25. Shirai M, Tsuchimochi H, Nagai H, Gray E, Pearson JT, Sonobe T, Yoshimoto M, Inagaki T, Fujii Y, Umetani K, Kuwahira I, Schwenke DO (2014). Pulmonary vascular tone is dependent on the central modulation of sympathetic nerve activity following chronic intermittent hypoxia. Basic Res Cardiol 109:432.10.1007/s00395014-0432-y

26. Vachiery JL, Adir Y, Barbera JA, Champion H, Coghlan JG, Cottin V, De Marco T, Galie N, Ghio S, Gibbs JS, Martinez F, Semigran M, Simonneau G, Wells A, Seeger W (2013). Pulmonary hypertension due to left heart diseases. J Am Coll Cardiol 62:D100-108.10.1016/j.jacc.2013.10.033

27. Vaillancourt M, Chia P, Sarji S, Nguyen J, Hoftman N, Ruffenach G, Eghbali M, Mahajan A, Umar S (2017). Autonomic nervous system involvement in pulmonary arterial hypertension. Respir Res 18:201.10.1186/s12931-017-0679-6

28. Velez-Roa S, Ciarka A, Najem B, Vachiery JL, Naeije R, van de Borne P (2004). Increased sympathetic nerve activity in pulmonary artery hypertension. Circulation 110:1308-1312.10.1161/01.CIR.0000140724.90898.D3

29. Zhang H, Zhang J, Xie DJ, Jiang X, Zhang FF, Chen SL (2016). Pulmonary artery denervation for treatment of a patient with pulmonary hypertension secondary to left heart disease. Pulm Circ 6:240-243.10.1086/685550

30. Zhou L, Zhang J, Jiang XM, Xie DJ, Wang JS, Li L, Li B, Wang ZM, Rothman AM, Lawrie A, Chen SL (2015). Pulmonary Artery Denervation Attenuates Pulmonary Arterial Remodeling in Dogs With Pulmonary Arterial Hypertension Induced by Dehydrogenized Monocrotaline. JACC Cardiovasc Interv 8:20132023.10.1016/j.jcin.2015.09.015

\section{FIGURE TITLES AND LEGENDS:}

Figure 1: Overview of study design and flowchart.

CMR: Cardiac magnetic resonance; CT: Computed tomography; PADN: Pulmonary artery denervation; PAP: Pulmonary artery pressure; PV: Pulmonary vein; RHC: Right heart catheterization.

Figure 2: Representative images showing the placement of the surgical radiofrequency ablation clamps at the level of the left (A) and right (B) PA branches and main PA trunk (C). Fluoroscopic images from the PA angiography (D) and positioning of the percutaneous ablation catheter in the PA bifurcation (E). 
Figure 3: Evolution of hemodynamic (upper panel) and CMR parameters (lower panel) in the PADN and sham groups. Data are median values and interquartile range. Measurements from both groups were obtained at the same time-points but curves are shifted to facilitate visualization.

PAP: pulmonary arterial pressure; PVR: pulmonary vascular resistance; RV: right ventricular; LV: left ventricular.

Figure 4: Representative images of the histopathological analysis: Morphometric study of the lung parenchyma vasculature; A: Double immunohistochemistry with anti-vonWillebrand factor (endothelial cells) and anti-smooth muscle actin (smooth muscle cells) antibodies to demonstrate the intimal thickening composed of SMA-positive cells, 20x; B: Verhoeff-van Gieson stain (elastic fibers in black) in intermediate $(100-300 \mu \mathrm{m}, 20 \mathrm{x})(\mathrm{B})$ and small vessels $(<100 \mu \mathrm{m}, 20 \mathrm{x})(\mathrm{C})$; D and $\mathrm{E}$ : Picrosirius red staining for the quantification of collagen content as a marker of interstitial fibrosis in the right (D) and left (E) ventricle, 10x; F: Double immunofluorescence technique with agglutinin (green), troponin I (red) and nuclei counterstained with DAPI in blue, for the evaluation of cardiomyocyte hypertrophy in the RV myocardium.

Figure 5: Representative images of the descriptive histological analysis of the pulmonary artery using Masson's trichrome stain in a sham control (A), an animal who underwent PADN using surgical bipolar radiofrequency clamps (B) and an animal treated with percutaneous catheter denervation (C and D). In the sham control (A), the autonomic nerve fibers are observed within the adventitial layer with healthy axons (arrows). At the medial layer, the smooth muscle fibers are normally organized. In an animal denervated using the surgical bipolar radiofrequency clamps (B), the nerve fibers in the adventitial layer are fibrotic and there are no visible axons (arrows). In this section there is also a vegetative ganglion with altered neurons (arrowhead). In the medial layer, smooth muscle fibers are denatured and replaced by connective tissue. The intimal layer is structurally normal. In an animal treated with the percutaneous catheter $(\mathrm{C}$ and $\mathrm{D})$, there are hemorrhagic areas in the medial layer (asterisk) with disarray of the surrounding smooth muscular fibers and an altered adventitial connective tissue matrix where the autonomic nerve fibers lay (arrows). However, these areas are localized (coincident with the zones of 
radiofrequency application) and in the same arterial slice healthy areas containing intact nerve fibers (arrowheads) are found. The intima layer is structurally normal. 


\section{TABLES:}

Table 1. Substudy 1. Baseline hemodynamic and CMR variables:

\begin{tabular}{|c|c|c|c|}
\hline & PADN $(n=6)$ & SHAM $(n=6)$ & $\mathbf{I}$ \\
\hline \multicolumn{4}{|c|}{ Right heart catheterization variables: } \\
\hline Weight $(\mathrm{Kg})$ & $33.0(30.0-38.5)$ & $31.0(27.5-36.5)$ & 0.589 \\
\hline Oxygen saturation $(\%)$ & $90.0(84.0-96.0)$ & $91.0(84.0-91.0)$ & 0.699 \\
\hline Heart rate $(\mathrm{bpm})$ & $77.5(71.0-90.0)$ & $78.3(75.0-80.0)$ & 0.818 \\
\hline Mean BP (mmHg) & $90.5(87.0-100.0)$ & $104.0(101.0-106.0)$ & 0.310 \\
\hline Systolic PAP (mmHg) & $40.8(33.0-44.0)$ & $38.0(35.0-42.0)$ & 0.589 \\
\hline Mean PAP (mmHg) & $32.0(26.0-35.0)$ & $27.5(26.0-31.5)$ & 0.394 \\
\hline Diastolic PAP (mmHg) & $24.0(19.0-25.5)$ & $20.0(17.0-24.0)$ & 0.132 \\
\hline RAP $(\mathrm{mmHg})$ & $2.0(0.0-3.0)$ & $1.5(-1.0-2.0)$ & 0.818 \\
\hline Indexed PVR $\left(W U^{*} m^{2}\right)$ & $5.9(4.6-6.6)$ & $4.7(4.1-6.2)$ & 0.394 \\
\hline $\mathrm{CI}\left(\mathrm{L} / \mathrm{min} / \mathrm{m}^{2}\right)$ & $3.9(3.5-4.8)$ & $4.7(3.0-5.2)$ & 0.818 \\
\hline LVEDP (mmHg) & $7.0(5.0-9.0)$ & $6.0(5.0-8.0)$ & 0.818 \\
\hline PCWP (mmHg) & $10.5(9.0-15.0)$ & $13.0(8.0-16.0)$ & 0.818 \\
\hline \multicolumn{4}{|l|}{ CMR parameters: } \\
\hline Indexed RVEDV $\left(\mathrm{ml} / \mathrm{m}^{2}\right)$ & $89.3(79.8-96.0)$ & $81.9(78.9-85.2)$ & 0.240 \\
\hline Indexed RVESV (ml/m²) & $39.1(37.7-43.6)$ & $34.0(32.9-34.7)$ & 0.132 \\
\hline $\operatorname{RVEF}(\%)$ & $54.9(52.4-57.6)$ & $59.3(56.3-60.4)$ & 0.065 \\
\hline Indexed RV mass $\left(\mathrm{g} / \mathrm{m}^{2}\right)$ & $24.3(18.9-25.7)$ & $23.1(19.5-26.3)$ & 0.699 \\
\hline Indexed LVEDV $\left(\mathrm{ml} / \mathrm{m}^{2}\right)$ & $82.7(81.2-84.0)$ & $89.4(86.3-95.7)$ & 0.132 \\
\hline Indexed LVESV $\left(\mathrm{ml} / \mathrm{m}^{2}\right)$ & $34.7(32.7-39.1)$ & $36.3(33.8-38.1)$ & 0.937 \\
\hline LVEF (\%) & $58.2(56.6-59.8)$ & $59.4(58.0-60.1)$ & 0.485 \\
\hline
\end{tabular}




\begin{tabular}{|l|l|l|l|}
\hline Indexed LV mass $\left(\mathrm{g} / \mathrm{m}^{2}\right)$ & $49.6(43.3-56.5)$ & $56.8(55.3-57.7)$ & 0.485 \\
\hline PA area $\left(\mathrm{cm}^{2}\right)$ & $7.1(5.8-8.0)$ & $6.4(5.1-7.5)$ & 0.310 \\
\hline PA elasticity $(\%)$ & $0.30(0.19-0.38)$ & $0.46(0.23-0.55)$ & 0.180 \\
\hline PA average velocity $(\mathrm{m} / \mathrm{s})$ & $9.0(8.6-10.7)$ & $10.1(9.0-12.8)$ & 0.240 \\
\hline Septal thickness $(\mathrm{mm})$ & $8.4(7.2-8.6)$ & $7.3(7.1-7.5)$ & 0.180 \\
\hline LV free wall thickness $(\mathrm{mm})$ & $6.8(6.3-7.4)$ & $6.2(6.0-6.6)$ & 0.394 \\
\hline RV free wall thickness $(\mathrm{mm})$ & $4.5(4.1-4.6)$ & $3.9(3.6-4.0)$ & 0.093 \\
\hline LV mass/volume ratio & $0.62(0.53-0.70)$ & $0.62(0.58-0.64)$ & 1.000 \\
\hline RV mass/volume ratio & $0.28(0.21-0.29)$ & $0.28(0.22-0.33)$ & 0.394 \\
\hline
\end{tabular}

BP: Blood pressure; CI: Cardiac index; LV: Left ventricular; LVEDP: Left ventricular end-diastolic pressure; LVEDV: Left ventricular end-diastolic volume; LVESV: Left ventricular end-systolic volume; LVEF: Left ventricular ejection fraction; PA: Pulmonary artery; PAP: Pulmonary arterial pressure; PCWP: Pulmonary capilar wedge pressure; PVR: Pulmonary vascular resistance; RAP: Right atrial pressure; RV: Right ventricular; RVEDV: Right ventricular end-diastolic volume; RVESV: Right ventricular end-systolic volume. 
Table 2. Substudy 1 . Hemodynamic parameters at the first (2-month) and second (3-month) followups:

\begin{tabular}{|c|c|c|c|c|c|c|}
\hline & \multicolumn{3}{|c|}{ Two-month follow-up } & \multicolumn{3}{|c|}{ Three-month follow-up } \\
\hline & PADN (n=6) & SHAM $(n=6)$ & $\mathbf{P}^{*}$ & PADN (n=6) & SHAM $(n=6)$ & $\mathbf{P}^{*}$ \\
\hline Weight $(\mathrm{Kg})$ & $50.5(47.0-54.0)$ & $52.0(45.5-61.5)$ & 0.167 & $63.3(61.0-68.5)$ & $73.5(65.0-76.0)$ & 0.010 \\
\hline $\begin{array}{l}\text { Oxygen } \\
\text { saturation (\%) }\end{array}$ & $91.0(88.0-94.0)$ & $95.5(90.0-98.0)$ & 0.897 & $91.0(87.0-95.0)$ & $90.5(88.0-94.0)$ & 0.876 \\
\hline Heart rate (bpm) & $55.0(45.0-63.0)$ & $69.0(62.0-80.0)$ & 0.072 & $56.5(52.0-70.0)$ & $66.0(61.0-71.0)$ & 0.270 \\
\hline $\begin{array}{l}\text { Mean BP } \\
(\mathrm{mmHg})\end{array}$ & $86.5(85.0-87.0)$ & $108.0(105.0-112.0)$ & 0.034 & $82.0(80.0-96.0)$ & $105.0(101.0-109.0)$ & 0.035 \\
\hline $\begin{array}{l}\text { Systolic PAP } \\
(\mathrm{mmHg})\end{array}$ & $53.5(45.0-62.0)$ & $47.0(41.0-50.0)$ & 0.635 & $47.5(39.0-63.0)$ & $47.5(43.0-53.0)$ & 0.528 \\
\hline $\begin{array}{l}\text { Mean PAP } \\
(\mathrm{mmHg})\end{array}$ & $36.0(30.0-41.0)$ & $37.0(30.0-39.0)$ & 0.850 & $35.0(31.0-43.0)$ & $35.0(33.0-39.0)$ & 0.236 \\
\hline $\begin{array}{l}\text { Diastolic PAP } \\
(\mathrm{mmHg})\end{array}$ & $24.5(22.0-29.0)$ & $28.0(22.0-28.0)$ & 0.617 & $26.0(24.0-29.0)$ & $27.5(24.0-30.0)$ & 0.287 \\
\hline $\begin{array}{l}\text { Indexed PVR } \\
\left(\mathrm{WU}^{*} \mathrm{~m}^{2}\right)\end{array}$ & $8.8(5.5-12.8)$ & $6.8(6.2-7.5)$ & 0.249 & $8.3(6.0-10.0)$ & $6.7(5.5-7.8)$ & 0.477 \\
\hline CI $\left(\mathrm{L} / \mathrm{min} / \mathrm{m}^{2}\right)$ & $3.7(3.0-4.2)$ & $4.5(3.6-5.0)$ & 0.166 & $3.8(3.1-4.2)$ & $3.9(3.7-4.5)$ & 0.194 \\
\hline $\begin{array}{l}\text { LVEDP } \\
(\mathrm{mmHg})\end{array}$ & $7.0(6.0-9.0)$ & $5.5(5.0-9.0)$ & 0.715 & $6.5(6.0-7.0)$ & $7.0(6.0-9.0)$ & 0.961 \\
\hline PCWP (mmHg) & $15.5(14.0-25.0)$ & $16.5(12.0-19.0)$ & 0.478 & $15.0(11.0-18.0)$ & $17.0(17.0-18.0)$ & 0.150 \\
\hline
\end{tabular}

BP: Blood pressure; CI: Cardiac index; LVEDP: Left ventricular end-diastolic pressure; PAP:

Pulmonary arterial pressure; PCWP: Pulmonary capilar wedge pressure; PVR: Pulmonary vascular resistance. *P value from ANCOVA test to evaluate changes adjusted by the baseline value. 
Table 3. Substudy 1. CMR parameters at the first (two-month) and second (three-month) follow-ups:

\begin{tabular}{|c|c|c|c|c|c|c|}
\hline & \multicolumn{3}{|c|}{ Two-month follow-up } & \multicolumn{3}{|c|}{ Three-month follow-up } \\
\hline & PADN $(n=6)$ & SHAM $(n=6)$ & $\mathbf{P}^{*}$ & PADN $(n=6)$ & SHAM $(n=6)$ & $\mathbf{P} *$ \\
\hline $\begin{array}{l}\text { iRVEDV } \\
\left(\mathrm{ml} / \mathrm{m}^{2}\right)\end{array}$ & $116.3(93.7-126.2)$ & $85.6(83.5-95.4)$ & 0.084 & $111.0(92.8-114.0)$ & $88.5(85.1-92.4)$ & $\mathbf{0 . 0 3 9}$ \\
\hline $\begin{array}{l}\text { iRVESV } \\
\left(\mathrm{ml} / \mathrm{m}^{2}\right)\end{array}$ & $49.0(39.8-57.7)$ & $34.5(30.9-36.8)$ & 0.061 & $43.0(38.6-44.6)$ & $32.4(30.5-33.8)$ & 0.002 \\
\hline $\operatorname{RVEF}(\%)$ & $55.2(51.2-64.8)$ & $59.7(59.4-64.0)$ & 0.150 & $60.3(55.5-62.8)$ & $62.8(61.6-63.7)$ & 0.064 \\
\hline iRV mass $\left(\mathrm{g} / \mathrm{m}^{2}\right)$ & $33.7(27.6-38.1)$ & $27.9(25.6-30.7)$ & 0.115 & $33.3(30.0-33.7)$ & $25.9(23.7-27.2)$ & 0.043 \\
\hline $\begin{array}{l}\text { iLVEDV } \\
\left(\mathrm{ml} / \mathrm{m}^{2}\right)\end{array}$ & $96.2(85.7-112.3)$ & $85.9(83.5-95.4)$ & 0.157 & $103.4(88.6-112.6)$ & $90.2(86.8-93.4)$ & 0.012 \\
\hline $\begin{array}{l}\text { iLVESV } \\
\left(\mathrm{ml} / \mathrm{m}^{2}\right)\end{array}$ & $37.1(31.3-38.5)$ & $35.6(30.2-37.5)$ & 0.600 & $38.3(33.2-39.4)$ & $33.4(29.5-36.9)$ & 0.184 \\
\hline LVEF (\%) & $62.6(61.1-66.7)$ & $62.4(57.6-63.6)$ & 0.478 & $63.3(60.6-66.6)$ & $61.9(59.6-65.1)$ & 0.833 \\
\hline iLV mass $\left(\mathrm{g} / \mathrm{m}^{2}\right)$ & $65.7(63.1-70.8)$ & $62.6(56.7-65.0)$ & 0.436 & $67.0(63.6-70.3)$ & $60.6(59.7-64.5)$ & 0.119 \\
\hline $\begin{array}{l}\text { PA average } \\
\text { velocity }(\mathrm{m} / \mathrm{s})\end{array}$ & $8.6(7.9-9.7)$ & $10.7(9.3-12.1)$ & 0.101 & $8.5(7.4-9.7)$ & $11.4(10.3-12.1)$ & 0.016 \\
\hline PA area & $8.4(7.6-8.8)$ & $9.3(8.3-9.8)$ & 0.159 & $9.5(9.4-10.5)$ & $9.6(9.5-9.7)$ & 0.966 \\
\hline $\begin{array}{l}\text { PA elasticity } \\
(\%)\end{array}$ & $0.36(0.29-0.49)$ & $0.40(0.23-0.51)$ & 0.871 & $0.42(0.32-0.56)$ & $0.41(0.36-0.42)$ & 0.864 \\
\hline $\begin{array}{l}\text { Septal thickness } \\
(\mathrm{mm})\end{array}$ & $8.9(8.2-9-9)$ & $8.8(8.3-9.4)$ & 0.267 & $9.7(8.4-10.6)$ & $9.2(9.0-9.6)$ & 0.318 \\
\hline
\end{tabular}




\begin{tabular}{|l|l|l|l|l|l|l|}
\hline $\begin{array}{l}\text { LV free wall } \\
\text { thickness (mm) }\end{array}$ & $8.0(7.4-8.9)$ & $7.0(6.3-7.9)$ & 0.255 & $8.3(7.1-8.9)$ & $7.7(7.3-8.1)$ & 0.942 \\
\hline $\begin{array}{l}\text { RV free wall } \\
\text { thickness (mm) }\end{array}$ & $5.3(4.7-5.9)$ & $4.9(4.3-5.5)$ & 0.439 & $5.7(5.5-6.4)$ & $5.3(4.5-5.8)$ & 0.435 \\
\hline $\begin{array}{l}\text { LV } \\
\text { mass/volume } \\
\text { ratio }\end{array}$ & $0.67(0.63-0.71)$ & $0.67(0.66-0.76)$ & 0.201 & $0.63(0.62-0.76)$ & $0.69(0.66-0.75)$ & 0.650 \\
\hline RV & $0.30(0.27-0.32)$ & $0.33(0.31-0.34)$ & 0.507 & $0.29(0.29-0.32)$ & $0.30(0.29-0.32)$ & 0.186 \\
mass/volume & & & & & & \\
\hline
\end{tabular}

LV: Left ventricular; LVEDV: Left ventricular end-diastolic volume; LVESV: Left ventricular endsystolic volume; LVEF: Left ventricular ejection fraction; PA: Pulmonary artery; RV: Right ventricular; RVEDV: Right ventricular end-diastolic volume; RVESV: Right ventricular end-systolic volume. *P value from ANCOVA test to evaluate changes adjusted by the baseline value. 
Table 4: Plasmatic NA and RAAS quantification:

\begin{tabular}{|c|c|c|c|c|c|c|c|c|c|}
\hline & \multicolumn{3}{|c|}{ Baseline } & \multicolumn{3}{|c|}{ 20-minutes post-PADN/sham } & \multicolumn{3}{|c|}{ Two-month follow-up } \\
\hline & $\begin{array}{c}\text { PADN } \\
(n=6)\end{array}$ & $\begin{array}{c}\text { SHAM } \\
(n=6)\end{array}$ & $\mathbf{P}$ & $\begin{array}{c}\text { PADN } \\
(n=6)\end{array}$ & $\begin{array}{c}\text { SHAM } \\
(n=6)\end{array}$ & $\mathbf{P}$ & $\begin{array}{l}\text { PADN } \\
(n=6)\end{array}$ & $\begin{array}{l}\text { SHAM } \\
(n=6)\end{array}$ & $\mathbf{P}$ \\
\hline $\begin{array}{l}\text { NA } \\
(\mathrm{pmol} / \mathrm{L})\end{array}$ & $\begin{array}{l}709.9 \\
(458.1- \\
2619.1)\end{array}$ & $\begin{array}{l}874.6 \\
(807.6- \\
1330.8)\end{array}$ & 0.937 & $\begin{array}{l}372.6 \\
(183.9- \\
611.4)\end{array}$ & $\begin{array}{l}264.5 \\
(191.4- \\
614.3)\end{array}$ & $\mathrm{P}=1.000$ & $\begin{array}{l}242.5 \\
(189.0- \\
623.2)\end{array}$ & $\begin{array}{l}318.8 \\
(209.8 \text { vs. } \\
463.6)\end{array}$ & 0.937 \\
\hline $\begin{array}{l}\text { NA (fold } \\
\text { change) }\end{array}$ & & & & $\begin{array}{l}-1.06 \\
(-1.92- \\
-0.27)\end{array}$ & $\begin{array}{l}-1.86 \\
(-2.80- \\
-0.55)\end{array}$ & 0.589 & $\begin{array}{l}-1.49 \\
(-2.10- \\
-0.22)\end{array}$ & $\begin{array}{l}-1.56 \\
(-2.67-- \\
0.90)\end{array}$ & 0.818 \\
\hline $\begin{array}{l}\text { AngII } \\
(\mathrm{pg} / \mathrm{mL})\end{array}$ & $\begin{array}{l}16.2(5.3- \\
25.1)\end{array}$ & $\begin{array}{l}23.5 \\
(11.7- \\
27.2)\end{array}$ & 0.762 & $\begin{array}{l}7.4(2.1- \\
47.5)\end{array}$ & $\begin{array}{l}20.9(9.2- \\
39.0)\end{array}$ & 0.610 & $\begin{array}{l}2.9(0.9- \\
11.5)\end{array}$ & $\begin{array}{l}9.6(4.3- \\
19.7)\end{array}$ & 0.352 \\
\hline $\begin{array}{l}\text { AngII (fold } \\
\text { change) }\end{array}$ & & & & $\begin{array}{l}0.6(-3.1- \\
1.8)\end{array}$ & $\begin{array}{l}-0.1(-1.5- \\
2.1)\end{array}$ & 0.914 & $\begin{array}{l}-2.0(-2.1-- \\
0.3)\end{array}$ & $\begin{array}{l}-1.3(-2.5- \\
1.1)\end{array}$ & 0.914 \\
\hline $\begin{array}{l}\text { Renin } \\
\text { (relative } \\
\text { fluorescenc } \\
\text { e at MaxV) }\end{array}$ & $\begin{array}{l}108.3 \\
(100.4- \\
126.3)\end{array}$ & $\begin{array}{l}102.1 \\
(77.3- \\
113.5)\end{array}$ & 0.476 & $\begin{array}{l}124.1 \\
(112.2- \\
153.3)\end{array}$ & $\begin{array}{l}115.3 \\
(106.3- \\
149.9)\end{array}$ & 0.914 & $\begin{array}{l}126.3 \\
(105.2- \\
162.2)\end{array}$ & $\begin{array}{l}148.9 \\
(137.2- \\
160.2)\end{array}$ & 0.352 \\
\hline $\begin{array}{l}\text { Renin (fold } \\
\text { change) }\end{array}$ & & & & $\begin{array}{l}0.08(- \\
0.3-0.4)\end{array}$ & $\begin{array}{l}0.5(0.1- \\
0.7)\end{array}$ & 0.352 & $\begin{array}{l}0.2(-0.3- \\
0.7)\end{array}$ & $\begin{array}{l}0.6(0.5- \\
0.9)\end{array}$ & 0.352 \\
\hline
\end{tabular}


AngII: Angiotensin II; NA: Noradrenaline.

Table 5: Local NA and RAAS activity:

\begin{tabular}{|c|c|c|c|c|c|c|}
\hline & \multicolumn{3}{|c|}{ Right ventricle } & \multicolumn{3}{|c|}{ Left ventricle } \\
\hline & $\begin{array}{l}\text { PADN } \\
(n=6)\end{array}$ & $\begin{array}{c}\text { SHAM } \\
(n=6)\end{array}$ & $\mathbf{P}$ & $\begin{array}{l}\text { PADN } \\
(n=6)\end{array}$ & $\begin{array}{l}\text { SHAM } \\
(n=6)\end{array}$ & $\mathbf{P}$ \\
\hline NA (nmol/L) & $\begin{array}{l}60.3(38.3- \\
93,3)\end{array}$ & $\begin{array}{l}137.7(88.4- \\
170.6)\end{array}$ & 0.041 & $\begin{array}{l}90.4(74.2- \\
141.7)\end{array}$ & $\begin{array}{l}86.8(68.5- \\
135.4)\end{array}$ & 0.699 \\
\hline AngII (pg/mL) & $6.4(2.7-22.1)$ & $4.7(4.3-6.8)$ & 0.699 & $7.9(5.4-8.0)$ & $11.4(3.5-11.8)$ & 0.240 \\
\hline $\begin{array}{l}\text { Renin (relative } \\
\text { fluorescence at } \\
\mathrm{MaxV} \text { ) }\end{array}$ & $\begin{array}{l}1083.9(469.1- \\
1403.8)\end{array}$ & $\begin{array}{l}1078.3(827.9- \\
1311.7)\end{array}$ & 0.937 & $\begin{array}{l}982.4(912.2- \\
1264.7)\end{array}$ & $\begin{array}{l}1053.6(844.8- \\
1302.5)\end{array}$ & 1.000 \\
\hline
\end{tabular}

AngII: Angiotensin II; NA: Noradrenaline. 
FIGURE 1

SUBSTUDY 1:

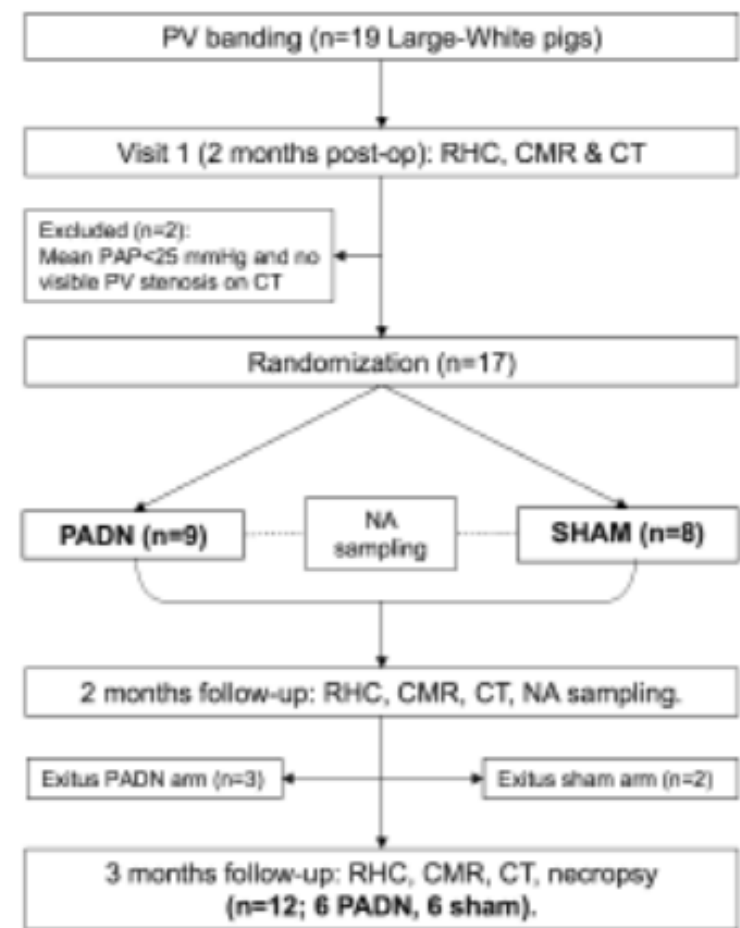

SUBSTUDY 2 :

Healthy Large-White pigs $60-80 \mathrm{Kg}(n=6)$

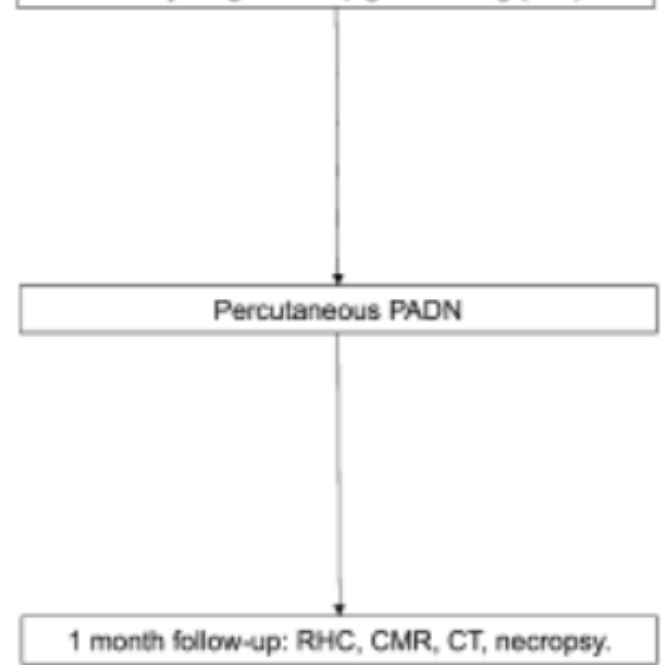


FIGURE 2
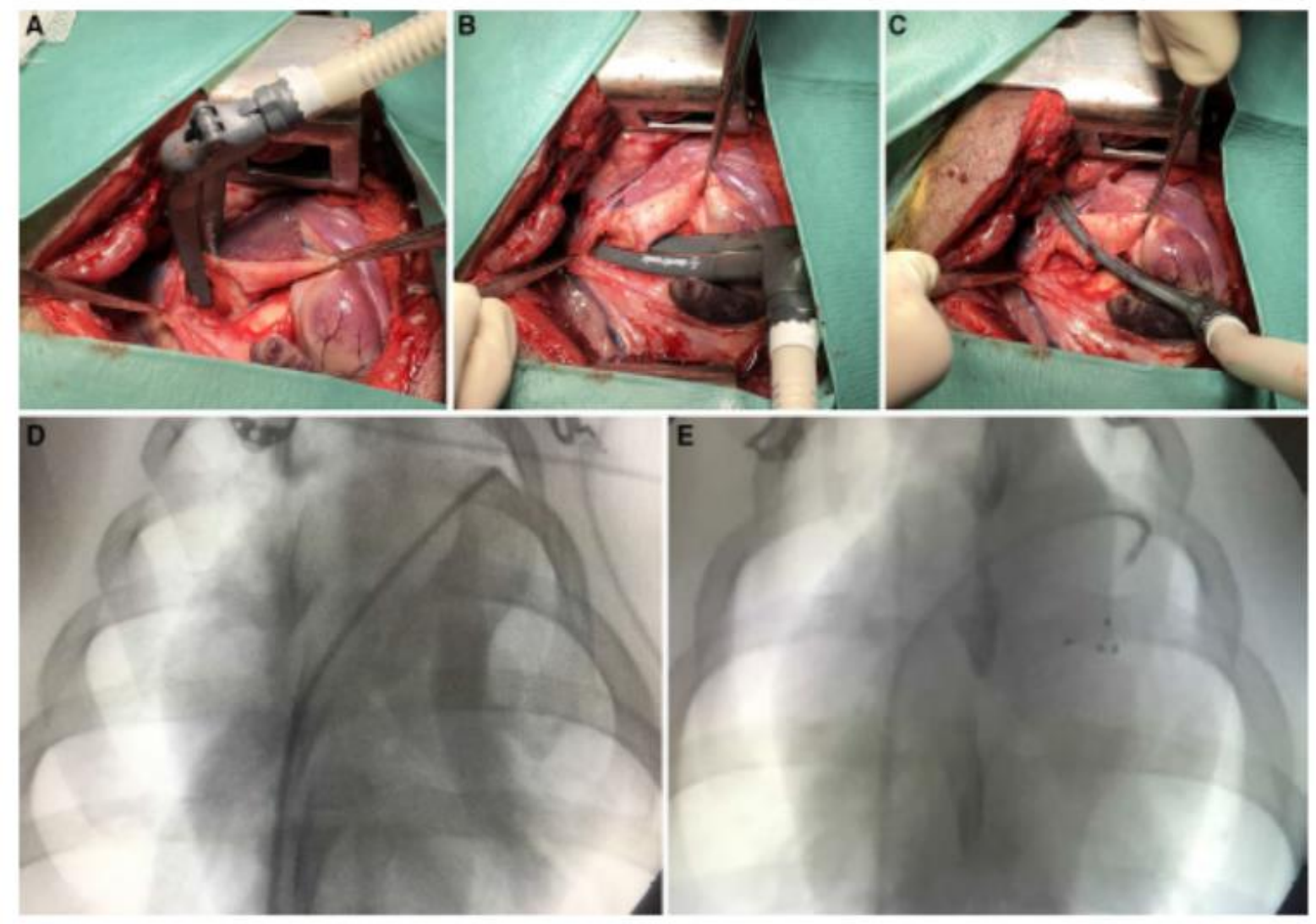
FIGURE 3
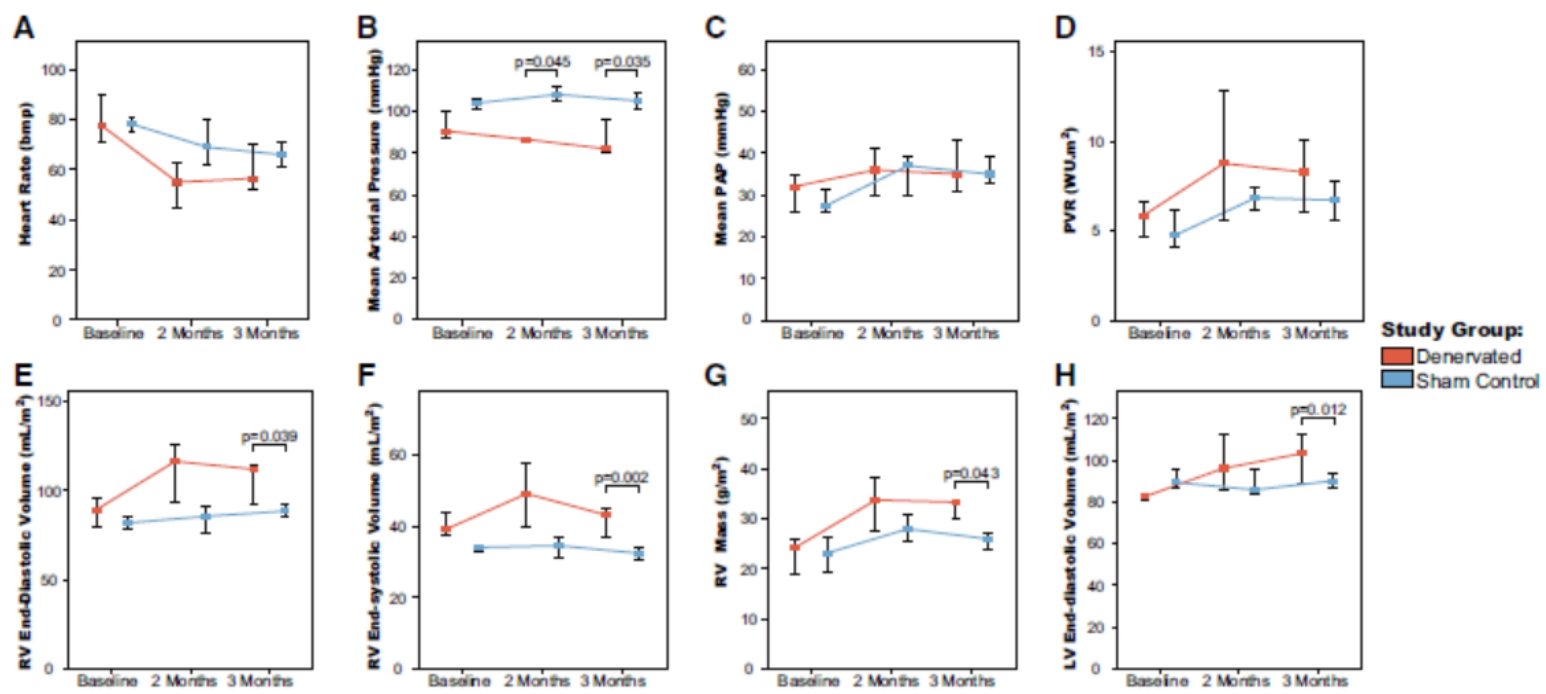

$\square$ Denervated

Sham Control 
FIGURE 4
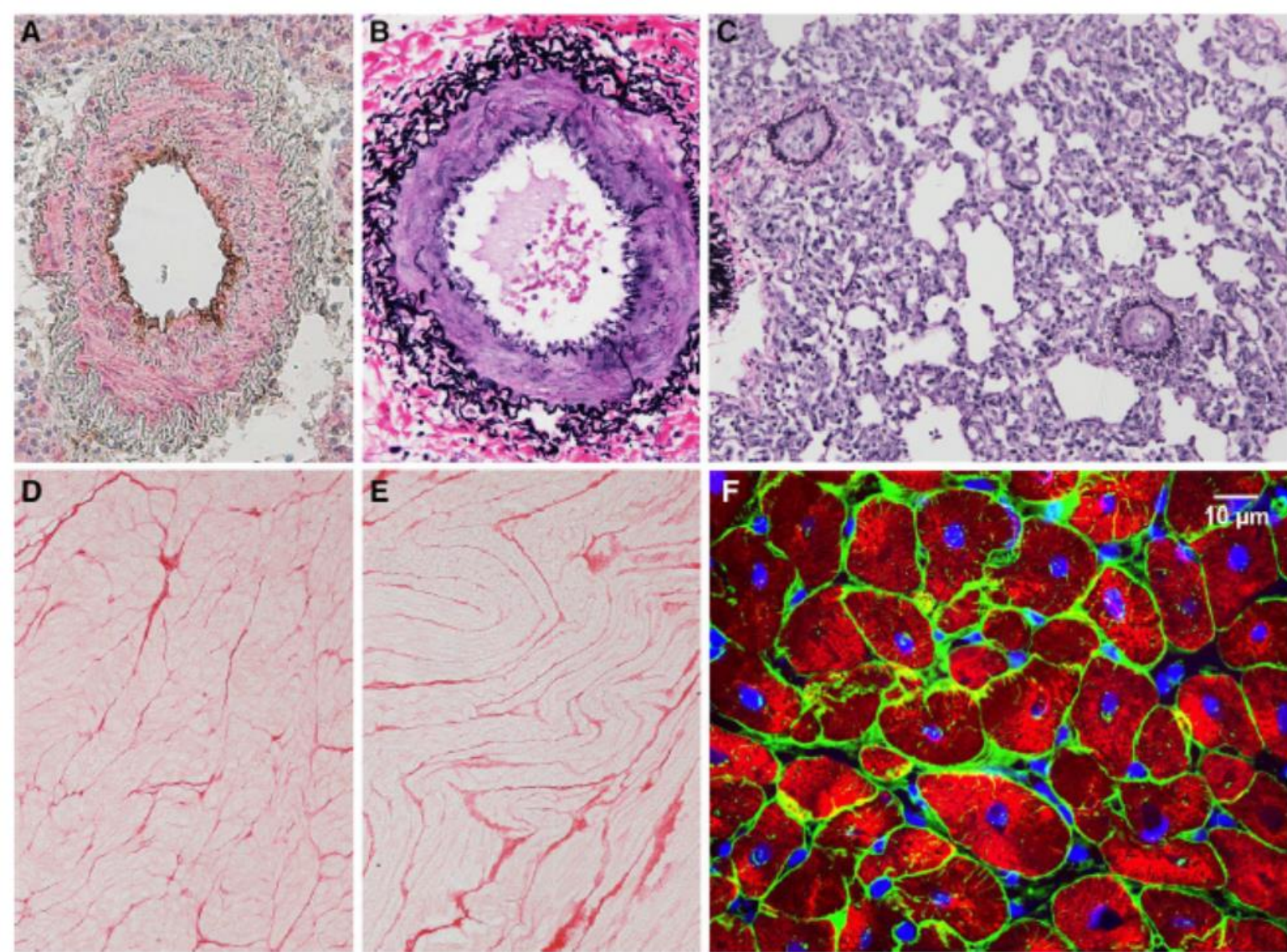
FIGURE 5
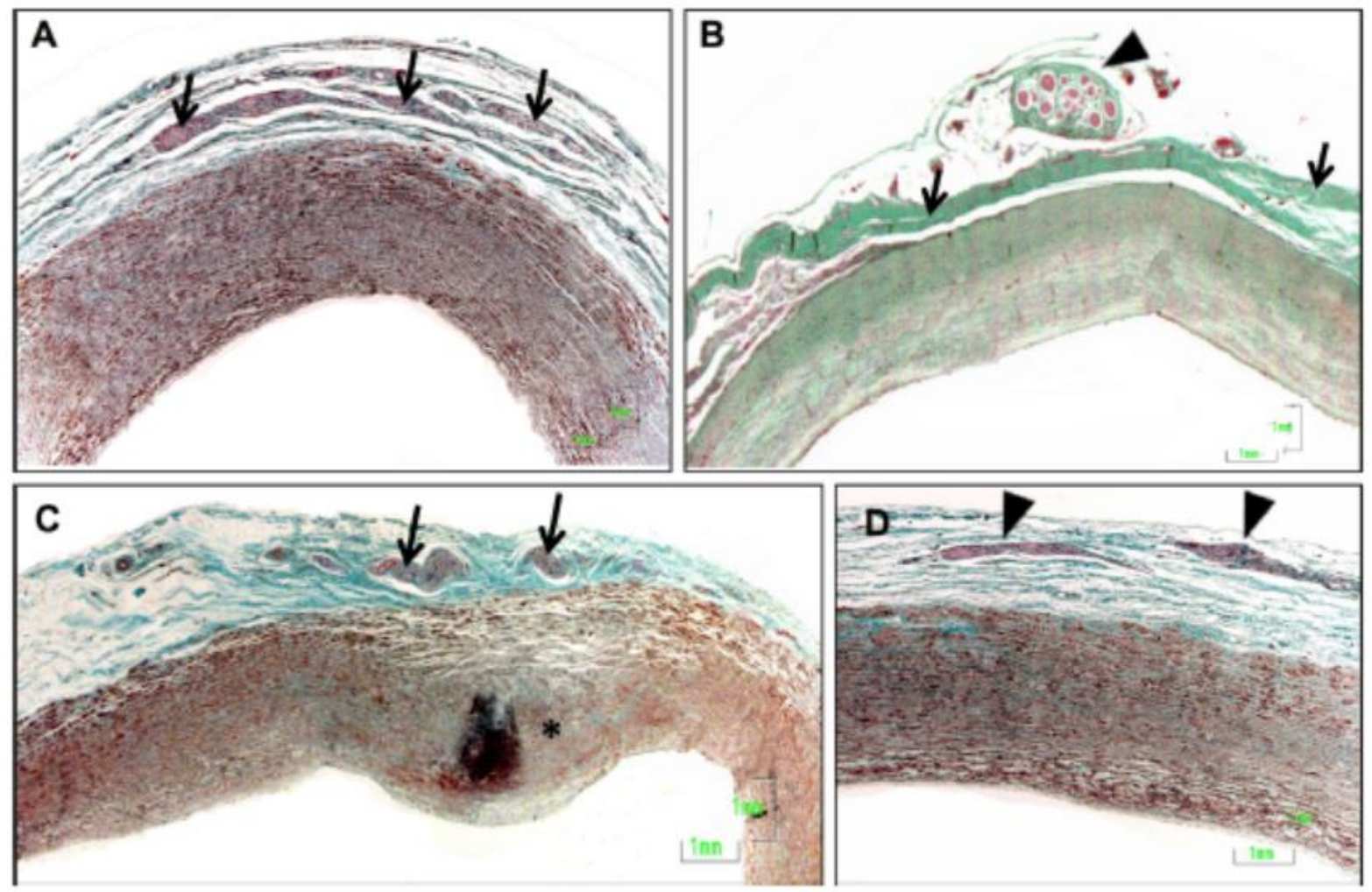